\title{
Dielectric Relaxation Studies of Binary Mixtures of Ethanol and Chlorobenzene in Benzene Solution from Microwave Absorption Data
}

\author{
Vimal Sharma and Nagesh Thakur \\ Department of Physics, H. P. University, Shimla - 171005, Himachal Pradesh, India \\ Reprint requests to V. S.; E-mail: vimal16sharma@yahoo.co.in
}

Z. Naturforsch. 63a, 93 - 97 (2008); received August 9, 2007

\begin{abstract}
Dielectric relaxation of different molar concentrations of ethanol $\left(\mathrm{C}_{2} \mathrm{H}_{5} \mathrm{OH}\right)$ in binary mixtures of ethanol and chlorobenzene in benzene solutions has been studied at $9.883 \mathrm{GHz}$ by using standard standing microwave techniques and Gopala Krishna's single frequency concentration variation method at different temperatures $\left(25^{\circ} \mathrm{C}, 30{ }^{\circ} \mathrm{C}, 35^{\circ} \mathrm{C}\right.$, and $\left.40{ }^{\circ} \mathrm{C}\right)$. It was found that the dielectric relaxation time varies linearly with variation in the molar concentration of ethanol in the whole concentration range of the binary mixture. Based upon these results the absence of solute-solute and the presence of solute-solvent type of molecular associations could be assumed. The energy parameters for the dielectric relaxation process of binary mixtures containing $50 \mathrm{~mol} \%$ of ethanol have been calculated at the given temperatures. Comparison has been made with the corresponding energy parameters for viscous flow processes. It was found that the dielectric relaxation process can be treated as the rate process like the viscous flow process.
\end{abstract}

Key words: Dielectric Relaxation; Binary Mixtures; Ethanol; Chlorobenzene; Microwave Absorption.

\section{Introduction}

Ethanol $\left(\mathrm{C}_{2} \mathrm{H}_{5} \mathrm{OH}\right)$ is a non-aqueous protic solvent [1]. It has the dielectric constant $\varepsilon^{\prime}=25.07$ and the dipole moment $\mu=1.70 \mathrm{D}$ [2]. Chlorobenzene $\left(\mathrm{C}_{6} \mathrm{H}_{5} \mathrm{Cl}\right)$ is an important non-aqueous solvent with the dielectric constant $\varepsilon^{\prime}=5.649$ and the dipole moment $\mu=1.69 \mathrm{D}$ [2]. It is used for manufacturing several important products, such as DDT, nitrochlorobenzene, aniline and silicone resins [3]. It is possible to prepare binary mixtures of ethanol and chlorobenzene having dielectric constants and dipole moment values in between those of ethanol and chlorobenzene. Ethanol and chlorobenzene have quite different static dielectric constants but exhibit similar values for the dipole moments. This motivated the authors to perform experimental work concerned with the dielectric relaxation process in binary mixtures of ethanol and chlorobenzene in order to understand the molecular association in the whole concentration range of ethanol in the binary mixtures.

The study of dielectric relaxation of polar liquids in non-polar solvents by microwave absorption techniques gives valuable information about the various types of molecular associations present in the solutions, because microwaves can detect weak molecular interactions [4-8]. The present investigation is concerned with the study of dielectric relaxation in binary mixtures of ethanol and chlorobenzene in the whole concentration range of ethanol in the binary mixtures, using standard standing microwave techniques as well as the method of varying the single frequency concentration by Gopala Krishna [9]. Measurements have been made for binary mixtures with different mole fractions of ethanol $(0.0,0.3,0.5,0.7$, and 1.0) at different temperatures $\left(25^{\circ} \mathrm{C}, 30{ }^{\circ} \mathrm{C}, 35^{\circ} \mathrm{C}\right.$, and $\left.40{ }^{\circ} \mathrm{C}\right)$. The energy parameters $\left(\Delta H_{\varepsilon}, \Delta F_{\varepsilon}, \Delta S_{\varepsilon}\right)$ have been calculated for the 0.5 -mole fraction of ethanol in the binary mixture. It was found that the dielectric relaxation process is a rate process like the viscous flow process. Solute-solvent types of molecular associations have been proposed for chlorobenzene and ethanol in benzene solution, whereas the absence of solute-solute associations has been found.

\section{Experimental}

Ethanol (AR grade) from Merck (Darmstadt, Germany) was distilled through a long vertical fractionating column. Benzene (GR grade) from E. Merck Ltd. (Mumbai, India) was dried by refluxing it over freshly cut sodium metal for $6-8 \mathrm{~h}$ and then distilled through 
a long vertical fractionating column. Chlorobenzene from Central Drug House (p) Ltd. (New Delhi, India) was distilled through a long vertical fractionating column. The middle fraction of each distilled solution was collected for use. The X-band microwave bench (frequency, $9.883 \mathrm{GHz}$ ) was used to measure the wavelengths in the dielectric and the voltage standing wave ratio (VSWR). The dielectric constant $\left(\varepsilon^{\prime}\right)$ and the dielectric loss $\left(\varepsilon^{\prime \prime}\right)$ of dilute solutions of binary mixtures of ethanol and chlorobenzene in benzene at various temperatures $\left(25{ }^{\circ} \mathrm{C}, 30{ }^{\circ} \mathrm{C}, 35{ }^{\circ} \mathrm{C}\right.$, and $\left.40{ }^{\circ} \mathrm{C}\right)$ were calculated following the microwave absorption technique of Heston et al. [10]. The temperature of the solution was controlled by thermostated water circulating around the dielectric cell. Following Gopala Krishna's single frequency concentration variation method [9], the dielectric relaxation time $(\tau)$ and the dipole moment $(\mu)$ were calculated. The viscosities and densities of the solutions were measured by an Ubbelohde viscometer and a sealable type of pycnometer, respectively.

\section{Results and Discussion}

The dielectric constant $\left(\varepsilon^{\prime}\right)$ and the dielectric loss $\left(\varepsilon^{\prime \prime}\right)$ of the binary mixtures (ethanol + chlorobenzene) in benzene solution have been determined by using the microwave absorption technique of Heston et al. [10]. The accuracy in the measurements of the $\varepsilon^{\prime}$ and $\varepsilon^{\prime \prime}$ values was $\pm 1 \%$ and $\pm 3 \%$, respectively. The following relations have been used to calculate $\varepsilon^{\prime}$ and $\varepsilon^{\prime \prime}$ :

$$
\begin{aligned}
& \varepsilon^{\prime}=\left(\frac{\lambda_{0}}{\lambda_{\mathrm{c}}}\right)^{2}+\left(\frac{\lambda_{0}}{\lambda_{\mathrm{d}}}\right)^{2}, \\
& \varepsilon^{\prime \prime}=\frac{2}{\pi}\left(\frac{\lambda_{0}}{\lambda_{\mathrm{d}}}\right)^{2} \frac{\lambda_{\mathrm{g}}}{\lambda_{\mathrm{d}}} \frac{\mathrm{d} \rho}{\mathrm{d} n} .
\end{aligned}
$$

Here $\lambda_{0}, \lambda_{\mathrm{c}}, \lambda_{\mathrm{g}}$, and $\lambda_{\mathrm{d}}$ are the wavelength of microwaves in free space, the cut off wavelength, the waveguide wavelength, and the wavelength in the waveguide filled with the solution, respectively, and $\rho$ is the inverse of the voltage standing wave ratio. $(\mathrm{d} \rho / \mathrm{d} n)$ is the slope of the curve of $\rho$ versus $n$. Here, $n$ is an integer $(n=1,2,3, \ldots)$, such that $\left(n \lambda_{\mathrm{d}} / 2\right)$ represents the length of the dielectrically filled waveguide. The variation of $\varepsilon^{\prime}$ and $\varepsilon^{\prime \prime}$ with the weight fraction of the solute in benzene for all binary mixtures was found to be linear (Figs. 1 and 2). This ensures the applicability of the Debye theory and hence Gopala Krishna's method in the studied concentration range of the binary

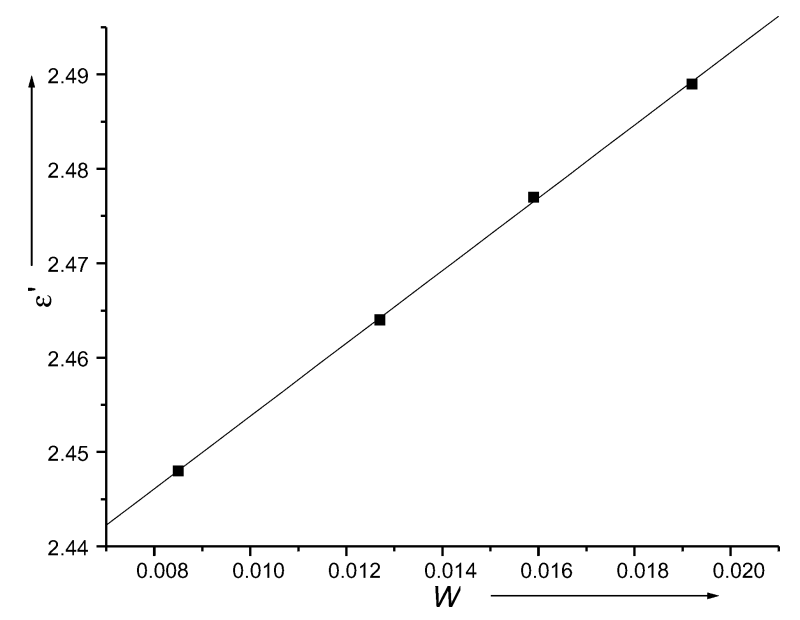

Fig. 1. Variation of dielectric constant $\left(\varepsilon^{\prime}\right)$ with weight fraction $(w)$ of $50 \mathrm{~mol} \%$ ethanol in (ethanol + chlorobenzene) binary mixture at $25^{\circ} \mathrm{C}$.

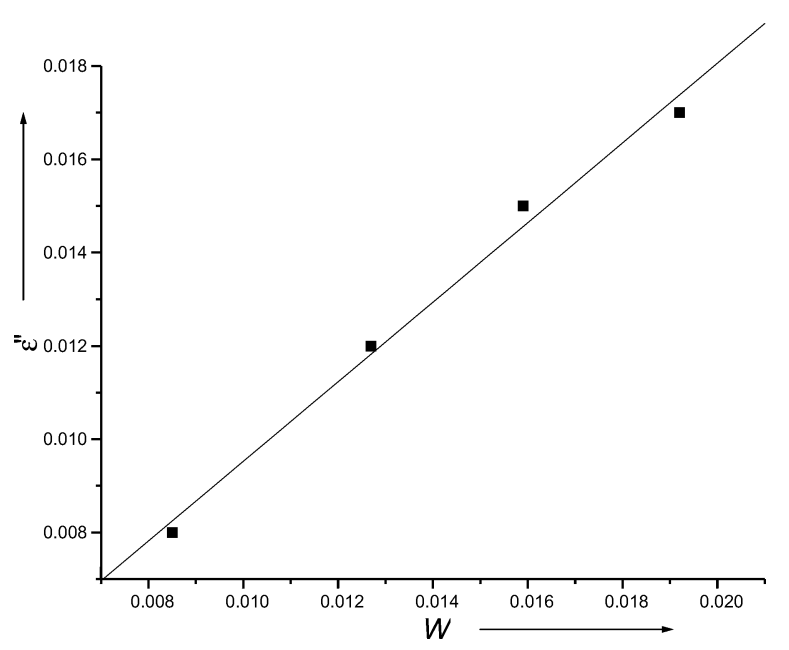

Fig. 2. Variation of dielectric loss $\left(\varepsilon^{\prime \prime}\right)$ with weight fraction (w) of $50 \mathrm{~mol} \%$ ethanol in (ethanol + chlorobenzene) binary mixture at $25^{\circ} \mathrm{C}$.

mixtures in the benzene solutions. The relaxation time $(\tau)$ and the dipole moment $(\mu)$ of the molecular entities were calculated using the single frequency concentration variation method of Gopala Krishna, according to the following equations:

$$
\begin{aligned}
X & =\frac{\varepsilon^{\prime 2}+\varepsilon^{\prime 2}+\varepsilon^{\prime}-2}{\left(\varepsilon^{\prime}+2\right)^{2}+\varepsilon^{\prime 2}}, \\
Y & =\frac{3 \varepsilon^{\prime \prime}}{\left(\varepsilon^{\prime}+2\right)^{2}+\varepsilon^{\prime \prime 2}}, \\
\tau & =\frac{\lambda_{0}}{2 \pi c}\left(\frac{\mathrm{d} Y}{\mathrm{~d} X}\right),
\end{aligned}
$$


Table 1. Dielectric relaxation time $(\tau)$ and dipole moment $(\mu)$ for different mole fractions of mixtures of ethanol and chlorobenzene in benzene solution at different temperatures.

\begin{tabular}{|c|c|c|c|c|}
\hline $\begin{array}{l}T, \\
{ }^{\circ} \mathrm{C}\end{array}$ & $\begin{array}{l}\text { Weight fraction of } \\
\text { solute in benzene }\end{array}$ & $\begin{array}{c}\text { Mole fraction } \\
\text { of ethanol in } \\
\text { binary mixture }\end{array}$ & $\begin{array}{c}\tau, \\
10^{-12} \mathrm{~s} \\
\end{array}$ & $\begin{array}{l}\mu \\
\mathrm{D}\end{array}$ \\
\hline \multirow[t]{9}{*}{$\overline{25}$} & $\begin{array}{l}0.0087,0.011 \\
0.0147,0.0167\end{array}$ & 0.00 & 4.88 & $\mu_{\mathrm{CB}}=1.63$ \\
\hline & $0.0093,0.0128$ & 0.30 & 3.93 & \\
\hline & $0.0161,0.0198$ & & & \\
\hline & $0.0085,0.0127$ & 0.50 & 3.40 & \\
\hline & $0.0159,0.0192$ & & & \\
\hline & $0.0087,0.0120$ & 0.70 & 2.95 & \\
\hline & $0.0149,0.0175$ & & & \\
\hline & $0.0096,0.0124$ & 1.00 & 2.48 & $\mu_{\mathrm{OH}}=1.62$ \\
\hline & $0.0142,0.0188$ & & & \\
\hline \multirow[t]{10}{*}{30} & $0.0087,0.011$ & 0.00 & 4.67 & $\mu_{\mathrm{CB}}=1.63$ \\
\hline & $0.0147,0.0167$ & & & \\
\hline & $0.0093,0.0128$ & 0.30 & 3.81 & \\
\hline & $0.0161,0.0198$ & & & \\
\hline & $0.0085,0.0127$ & 0.50 & 3.26 & \\
\hline & $0.0159,0.0192$ & & & \\
\hline & $0.0087,0.0120$ & 0.70 & 2.84 & \\
\hline & $0.0149,0.0175$ & & & \\
\hline & $0.0096,0.0124$ & 1.00 & 2.27 & $\mu_{\mathrm{OH}}=1.64$ \\
\hline & $0.0142,0.0188$ & & & \\
\hline \multirow[t]{10}{*}{35} & $0.0087,0.011$ & 0.00 & 4.46 & $\mu_{\mathrm{CB}}=1.66$ \\
\hline & $0.0147,0.0167$ & & & \\
\hline & $0.0093,0.0128$ & 0.30 & 3.64 & \\
\hline & $0.0161,0.0198$ & & & \\
\hline & $0.0085,0.0127$ & 0.50 & 3.08 & \\
\hline & $0.0159,0.0192$ & & & \\
\hline & $0.0087,0.0120$ & 0.70 & 2.73 & \\
\hline & $0.0149,0.0175$ & & & \\
\hline & $0.0096,0.0124$ & 1.00 & 2.09 & $\mu_{\mathrm{OH}}=1.66$ \\
\hline & $0.0142,0.0188$ & & & \\
\hline \multirow[t]{10}{*}{40} & $0.0087,0.011$ & 0.00 & 4.26 & $\mu_{\mathrm{CB}}=1.70$ \\
\hline & $0.0147,0.0167$ & & & \\
\hline & $0.0093,0.0128$ & 0.30 & 3.49 & \\
\hline & $0.0161,0.0198$ & & & \\
\hline & $0.0085,0.0127$ & 0.50 & 2.92 & \\
\hline & $0.0159,0.0192$ & & & \\
\hline & $0.0087,0.0120$ & 0.70 & 2.58 & \\
\hline & $0.0149,0.0175$ & & & \\
\hline & $0.0096,0.0124$ & 1.00 & 1.92 & $\mu_{\mathrm{OH}}=1.68$ \\
\hline & $0.0142,0.0188$ & & & \\
\hline
\end{tabular}

and

$$
\mu^{2}=\frac{9 k T M}{4 \pi N d}\left[1+\left(\frac{\mathrm{d} Y}{\mathrm{~d} X}\right)^{2}\right] \frac{\mathrm{d} X}{\mathrm{~d} W} .
$$

The measured dipole moments of ethanol and chlorobenzene were found to be very near to the literature values. This shows that pure ethanol and pure chlorobenzene exist in the monomer form in benzene solution.

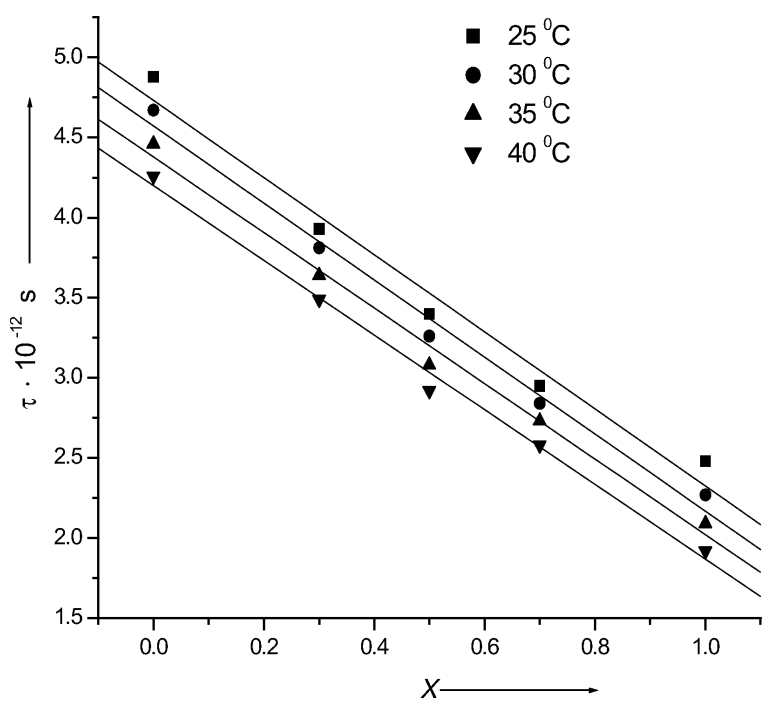

Fig. 3. Variation of relaxation time with mole fraction $(x)$ of ethanol in (ethanol + chlorobenzene) mixture in benzene solution at different temperatures.

Table 1 represents the values of the dielectric relaxation time $(\tau)$ and of the dipole moment $(\mu)$ for the binary mixtures of ethanol and chlorobenzene in benzene solution at different temperatures $\left(25{ }^{\circ} \mathrm{C}, 30^{\circ} \mathrm{C}\right.$, $35^{\circ} \mathrm{C}$, and $40^{\circ} \mathrm{C}$ ) for different mole fractions of ethanol in the binary mixtures. A linear dependence of the relaxation time on the increase of the mole fraction of ethanol in the binary mixtures (ethanol + chlorobenzene) at all temperatures has been observed. The relaxation time depends on the size and shape of the rotating molecular entities in the solution. The linear change of the relaxation time, from its value corresponding to one single constituent to the value which corresponds to the pure other constituent, with varying mole fraction in the whole concentration range may be taken as the absence of any solute-solute association in the mixture [11]. On the other hand the non-linear variation of the relaxation time with the mole fraction is interpreted as a possible solute-solute molecular association in the binary mixture [12]. In the present study, the linear dependence of the relaxation time on the change of the mole fraction of ethanol in the binary mixture allows the conclusion of the absence of solute-solute molecular associations (Fig. 3).

There was a small variation in the dipole moments of ethanol and chlorobenzene in benzene solution with increasing temperature. This could possibly be explained on the basis of solvent effects [13]. The change in the dipole moment with temperature may be due 


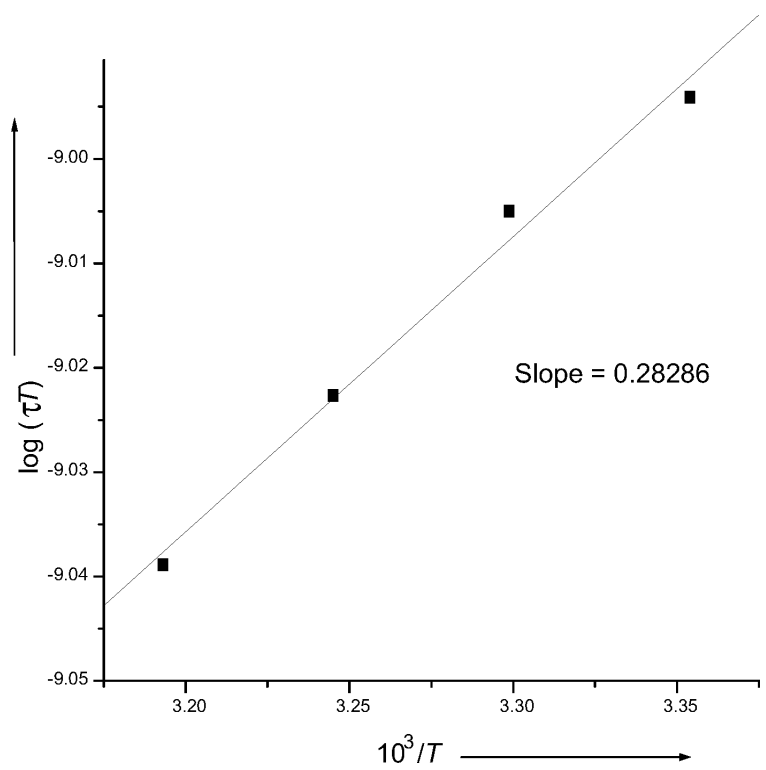

Fig. $4 . \log (\tau T)$ versus $10^{3} / T$.

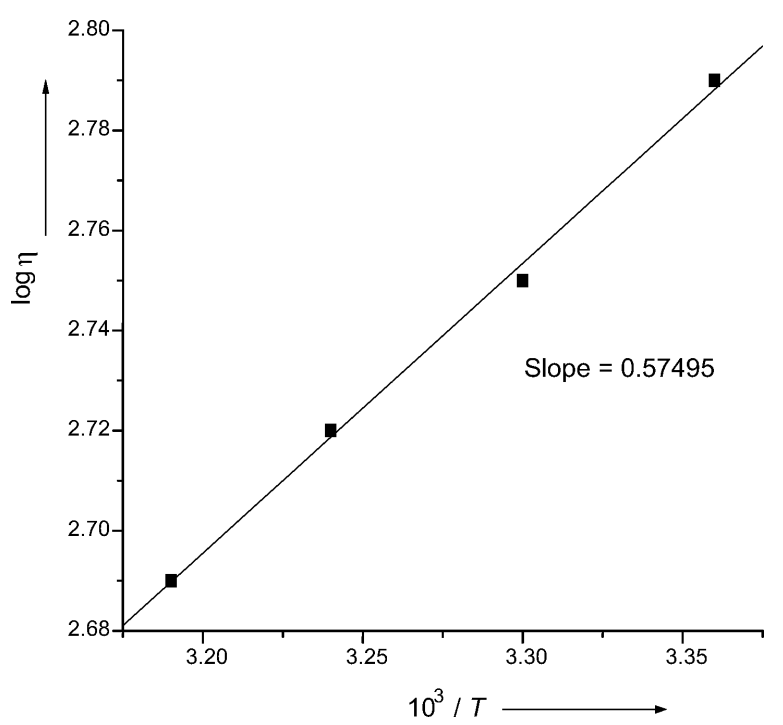

Fig. 5. $\log (\eta)$ versus $10^{3} / T$.

to the stretching of the bond moments and to the change in the bond angles. This supports the existence of a solute-solvent type of molecular association for ethanol in the benzene solution. Plots of $\log (\tau T)$ versus $10^{3} / T$ (Fig. 4) and $\log (\eta)$ versus $10^{3} / T$ (Fig. 5) are found to be linear, which indicates that both the dielectric relaxation process and the viscous flow can be treated as rate processes.
Table 2. Enthalpies of activation $\left(\Delta H_{\varepsilon}, \Delta H_{\eta}\right.$ in $\left.\mathrm{kJ} \mathrm{mol}^{-1}\right)$, free energies of activation $\left(\Delta F_{\varepsilon}, \Delta F_{\eta}\right.$ in $\left.\mathrm{kJ} \mathrm{mol}^{-1}\right)$, and entropies of activation $\left(\Delta S_{\mathcal{\varepsilon}}, \Delta S_{\eta}\right.$ in $\left.\mathrm{kJ} \mathrm{mol}^{-1} \mathrm{~K}^{-1}\right)$ for the mixtures (ethanol + chlorobenzene) containing $50 \mathrm{~mol} \%$ of ethanol in benzene solution.

\begin{tabular}{ccccccc}
\hline $\begin{array}{c}\text { Temperature, } \\
{ }^{\circ} \mathrm{C}\end{array}$ & $\begin{array}{c}\Delta H_{\varepsilon} \\
\pm 0.17\end{array}$ & $\begin{array}{c}\Delta F_{\varepsilon} \\
\pm 0.14\end{array}$ & $\begin{array}{c}\Delta S_{\varepsilon} \\
\pm 0.31\end{array}$ & $\Delta H_{\eta}$ & $\Delta F_{\eta}$ & $\Delta S_{\eta}$ \\
\hline 25 & 5.420 & 7.569 & -7.209 & 11.019 & 12.198 & -3.956 \\
30 & 5.420 & 7.632 & -7.297 & 11.019 & 12.228 & -3.985 \\
35 & 5.420 & 7.653 & -7.247 & 11.019 & 12.253 & -4.002 \\
40 & 5.420 & 7.682 & -7.226 & 11.019 & 12.315 & -4.140 \\
\hline
\end{tabular}

Using Eyring's rate equations [14], the energy parameters $\left(\Delta H_{\varepsilon}, \Delta F_{\varepsilon}, \Delta S_{\varepsilon}\right)$ of the dielectric relaxation process of $50 \mathrm{~mol} \%$ ethanol in the binary mixture in benzene have been calculated. These energy parameters have been compared with the viscosity parameters for the flow of benzene solution as shown in Table 2. It was found that the free energy of activation $\left(\Delta F_{\varepsilon}\right)$ of the dielectric relaxation process is less than the free energy of activation $\left(\Delta F_{\eta}\right)$ of the viscous flow process. This may be explained with the argument that the dielectric relaxation process involves the rotation of molecular entities, whereas in the flow process the rotational as well as the translational motions of the molecules are involved [15]. The enthalpy of activation depends on the local environment of the molecules. The enthalpy of activation $\left(\Delta H_{\varepsilon}\right)$ of the dielectric relaxation process was found to be different from the enthalpy of activation $\left(\Delta H_{\eta}\right)$ of a viscous flow process. This difference shows that the dielectric relaxation process comprises different types of bonding and a breaking of the bonding to different extents.

According to Branin and Smyth [16], a negative value of the entropy of activation indicates that a comparatively smaller number of configurations is possible in an activated state, which is more ordered in comparison to the normal state. This again indicates the presence of a cooperative orientation of the molecules by the steric forces or by strong dipole-dipole interactions with the dipole being better aligned in an activated state. However, the positive value of the activation entropy indicates that the activated state is more disordered. In the present case it is observed that the change in entropy of the dielectric relaxation process is negative, indicating that the environment of the system is cooperative like that of the activated viscous flow state. 
[1] G. Mamantov, Characterization of Solutes in NonAqueous Solvents, Plenum Press, New York and London 1976, p. 26.

[2] N.E. Hill, W. E. Vaughan, A. H. Price, and M. Davies, Dielectric Properties and Molecular Behaviour, Van Nostrand-Reinhold, London 1969, p. 2.

[3] E. Kilner and D. M. Samuel, Applied Organic Chemistry, Macdonald and Evans Ltd., London 1960, p. 244.

[4] N. Thakur and D. R. Sharma, Indian J. Pure Appl. Phys. 38, 328 (2000).

[5] A. D. Vyas and V. A. Rana, Indian J. Pure Appl. Phys. 40, 69 (2002).

[6] V.S. Rangra and D. R. Sharma, Indian J. Pure Appl. Phys. 78B, 111 (2004).

[7] A. Chaudhari, S. Ahire, and S. C. Mehrotra, J. Mol. Liq. 94, 17 (2001).

[8] G. D. Rewar and D. Bhatnagar, Indian J. Pure Appl. Phys. 40, 430 (2002).
[9] K. V. Gopala Krishna, Trans. Faraday Soc. 33, 767 (1957).

[10] W. M. Heston, A. D. Franklin, E. L. Hennely, and C. P. Smyth, J. Am. Chem. Soc. 72, 3443 (1950).

[11] V.S. Rangra and D. R. Sharma, Indian J. Pure Appl. Phys. 41, 630 (2003).

[12] N. Thakur and D. R. Sharma, Indian J. Pure Appl. Phys. 38, 328 (2000).

[13] N.E. Hill, W.E. Vaughan, A. H. Price, and M. Davies, Dielectric Properties and Molecular Behaviour, Van Nostrand-Reinhold, London 1969, p. 253.

[14] H. Eyring, S. Glasstone, and K. J. Laidler, Theory of Rate Process, Mc Graw-Hill, New York 1941, p. 541.

[15] N. Srinivasan, S. Kumar, and S. Krishnan, Indian J. Pure Appl. Phys. 41, 876 (2003).

[16] F. H. Branin and C. P. Smyth, J. Chem. Phys. 42, 2503 (1965). 